\title{
Studies on the Immaturity of the ADH-Dependent cAMP System in Conscious Newborn Piglets- Possible Impairing Effects of Renal Prostaglandins
}

\author{
RÜDIGER JOPPICH, ${ }^{(2)}{ }^{(2)}$ DIETER A. HÄBERLE. AND PETER C. WEBER \\ Universitäts-Kinderklinik [R.J.], Physiologisches Institut [D. A. H.], and Medizinische Klinik Innenstadt [P. C. W.]. \\ University of Munich, 8000 Munich 2. Federal Republic of Germany
}

\begin{abstract}
Summary
In 24 conscious newborn piglets the effects of $20 \mu \mathrm{g} / \mathrm{kg}$ body weight IV 1-deamino-8-D-arginine-vasopressin (DDAVP) in group $1,5 \mathrm{mg} / \mathrm{kg} P O$ indomethacin in group 2 , and the combined effects of both drugs in group 3 were studied by measuring urinary flow rate, urinary osmolality, creatinine clearance, total urinary and nephrogenous cyclic-adenosine $3^{\prime}: 5^{\prime}$-monophosphate (cAMP) excretion, medullary cAMP content, and renal prostaglandin $(P G) E_{2}$ and PGF $F_{2 a}$ excretion. DDAVP alone had no significant effects on the above parameters, whereas indomethacin alone reduced only the PG excretion significantly. When both drugs were administered simultaneously, urinary concentration increased significantly (urinary flow rate decreased from $2.4 \pm 0.4$ to $1.4 \pm 0.3 \mathrm{ml} / \mathrm{hr}$ (means \pm S.E.), and urinary osmolality increased from $444 \pm 29$ to $552 \pm 33 \mathrm{mOsm} / \mathrm{liter}$ ). Total urinary and nephrogenous cAMP excretion increased from $590 \pm 48$ to $854 \pm 78$ and $302 \pm 36$ to $590 \pm 81 \mathrm{pmoles} / \mathrm{hr} / \mathrm{g}$ kidney weight, respectively, whereas $\mathrm{PGE}_{2}$ and $P G F_{2 n}$ decreased from $249 \pm 33$ to $19 \pm 4$ and $192 \pm 32$ to 43 $\pm 7 \mathrm{pg} / \mathrm{hr} / \mathrm{g}$ kidney weight, respectively. In addition, medullary cAMP content was considerably higher in group $3(2010 \pm 200$ pmoles/g medulla) than that observed in the control (1187 \pm 137$)$, DDAVP $(1218 \pm 115)$, and indomethacin $(1230 \pm 168)$ groups.
\end{abstract}

\section{Speculation}

During the neonatal period, renal prostaglandins inhibit the antidiuretic hormone-dependent cyclic adenosine 3 : $5^{\prime}$-monophosphate system.

Recent in vivo studies provided evidence that the restricted urinary concentrating capacity of the neonatal kidney results from the inability of the medullary cyclic adenosine $3^{\prime}: 5^{\prime}$-monophosphate (cAMP) system to accumulate cAMP sufficiently in the presence of antidiuretic hormone (ADH) (14) in addition to the reduced glomerular filtration rate (2), the structural immaturity of the loop of Henle (5), and the low excretion rate of urea (7). Some observations indicate that the unresponsiveness of the cAMP system to ADH may result not only from a functional immaturity of the medullary adenylate cyclase $(20,22)$, but additionally from the interference of renal prostaglandins (PGs) of the E-series with the hydro-osmotic action of ADH. This view is based on the following observations: (1) in isolated collecting ducts, the effect of $\mathrm{ADH}$ on the water permeability was blunted when $\mathrm{PGE}_{1}$ was applied (10); (2) conversely, in adult mammals when PG synthesis was inhibited the effect of $\mathrm{ADH}$ on water reabsorption was increased $(1,3,8,17)$.

High concentrations of PGs were found in urine of fetal lambs (23), and high $\mathrm{PGE}_{2}$ levels were inversely correlated with urinary cAMP excretion in premature infants (15). If a relatively high $\mathrm{PGE}_{2}$ formation in the kidney of neonates is indeed a restrictive parameter for renal medullary cAMP accumulation, it should be possible to increase the effect of $\mathrm{ADH}$ on urinary concentration by inhibiting PG synthesis.

Therefore, we measured urinary concentration in newborn piglets, both before and after the administration of either DDAVP or indomethacin alone and after administration of DDAVP plus indomethacin. The studies were performed in conscious animals because it has been shown that in the unanaesthetized animal indomethacin does not change renal blood flow (24), whereas administration of this drug in the anaesthetized dog is associated with a marked fall in renal blood flow (16).

\section{MATERIALS AND METHODS}

\section{EXPERIMENTAL}

Studies were carried out on 24 male conscious piglets (strain, Deutsche Landrasse) within the first $24 \mathrm{hr}$ after birth. The animals weighed between 1000 and $1700 \mathrm{~g}$ and had free access to suck. The following protocol was used.

Control Period. In all animals used, first all urine in the bladder was removed by puncturing the bladder suprapubically. Then the urethra was closed by glue and plaster, and each animal was returned to the pigsty and allowed to suck ad libitum. Four hr later, the bladder was punctured again, and the urine was withdrawn quantitatively for control measurements. Simultaneously, a blood sample was taken from the brachiocephalic vein for measurement of cAMP and creatinine.

Experimental Period. After this control period, six piglets received an intravenous (IV) injection (brachiocephalic vein) of DDAVP $[20 \mu \mathrm{g} / \mathrm{kg}$ body weight (b.w.)] (1-deamino-8-D-argininevasopressin; Ferring) (group 1); seven piglets were given indomethacin (Sharp and Dohme) $(5 \mathrm{mg} / \mathrm{kg} \mathrm{b.w}$.) by a stomach tube (group 2); and nine piglets were given a combination of DDAVP $(20 \mu \mathrm{g} / \mathrm{kg} \mathrm{b.w}$.) IV and indomethacin $(5 \mathrm{mg} / \mathrm{kg} \mathrm{b.w}$.) by a stomach tube (group 3). All animals were removed from the litter and maintained in a temperature-controlled cage without any fluid. Four hr later, urine and blood were sampled in the same way, as described above. Then the animals were anaesthetized by an injection of Inactin $(100 \mathrm{mg} / \mathrm{kg}$ ) (Byk Gulden) IP, both kidneys were removed immediately and frozen in liquid nitrogen and stored at $-20^{\circ} \mathrm{C}$ until tissue analyses were performed. For control measurements of medullary cAMP content in two piglets, the kidneys were removed after the control period without administration of either DDAVP or indomethacin.

\section{ANALYTICAL METHODS}

The blood samples for the determination of cAMP were collected in precooled plastic tubes containing EDTA and centrifuged at $2^{\circ} \mathrm{C}$. Then the plasma was stored at $-20^{\circ} \mathrm{C}$ until the determination of cAMP was performed.

cAMP was determined in urine and plasma by Gilman's method (9) using the test kit of Boehringer (Mannheim). The urine was 
analysed without any further preparation. The plasma was prepared as described by Hamet et al. (11). Urinary $\mathrm{PGE}_{2}$ and $\mathrm{PGF}_{2 a}$ were measured radioimmunologically (21). Urine and plasma osmolalities were measured by freezing point depression. Creatinine was determined according to Jaffe (4). In medullary tissue, cAMP was determined in the following way. The frozen kidneys were placed on an aluminum plate and kept at a temperature of $-10^{\circ} \mathrm{C}$. The medulla was separated from the cortex and dissected into slices of 100 to $200 \mathrm{mg}$. Two $\mathrm{ml}$ of ice cold $1 \mathrm{~N}$ perchloric acid were added to the slices. After homogenisation in a Potter $\mathbf{S}$ homogenizer (Braun Melsungen), [ $\left.{ }^{3} \mathrm{H}\right] \mathrm{cAMP}$ (for recovery) was added. The homogenate was centrifuged, and the pellet was discarded. The supernatant was purified by aluminum oxide columns as described by Jacobs et al. (13). cAMP and cyclicguanosine $3^{\prime}: 5^{\prime}$-monophosphate were separated by column chromatography using Dowex AG 1-X2, 200 to 400 mesh, equilibrated with 0.1 formic acid and eluted with $5 \mathrm{ml} 2 \mathrm{~N}$ formic acid. The eluates were lyophilized, reconstituted in $1 \mathrm{ml}$ of double-distilled water, and added to the assay system. The measurements were corrected for recovery (about 60\%).

\section{CALCUlation}

cAMP produced by the kidney ("nephrogenous cAMP") was calculated from the difference between the renal excretion rate in urine ("total urinary cAMP") and the rate filtered by the glomeruli (creatinine clearance $\times$ plasma cAMP). All results were expressed as means \pm S.E. Student's $t$ test was used to test for a significant difference between the mean values.

\section{RESULTS}

Table 1 summarizes the mean values of urinary concentration, creatinine clearance, cAMP, and renal PGs in the three experimental groups (group 1, DDAVP; group 2, indomethacin; group 3 , DDAVP plus indomethacin). In control conditions ("before") the results were not significantly different from each other except the excretion rate of $\mathrm{PGF}_{2 \pi}$ in the DDAVP and the indomethacin group $(P<0.01)$. Table 1 shows that only when DDAVP and indomethacin were administered together urinary osmolality raised and urinary flow rate decreased significantly. This occurred with an unchanged creatinine clearance.

Figure 1 demonstrates that this effect of the combined administration of DDAVP and indomethacin in group 3 on the urinary concentrating mechanism was paralleled by an increase of total urinary and nephrogenous cAMP excretion, whereas DDAVP or indomethacin when administered alone did not have any influence. In addition, in group 3, cAMP content of the renal medulla was significantly higher $(P<0.001)$ than that observed in the control, DDAVP, or indomethacin groups (Table 2 ).

$\mathrm{PGE}_{2}$ was excreted in all three groups in predominance over $\mathrm{PGF}_{2 a}$. A significant decrease of both $\mathrm{PGE}_{2}$ and $\mathrm{PGF}_{2,}$ was observed after administration of indomethacin alone or in combination with DDAVP, whereas DDAVP alone did not influence the PG excretion significantly (Fig. 2).

\section{DISCUSSION}

In this study on conscious newborn piglets two main findings were obtained: (1) even supramaximal doses of DDAVP were

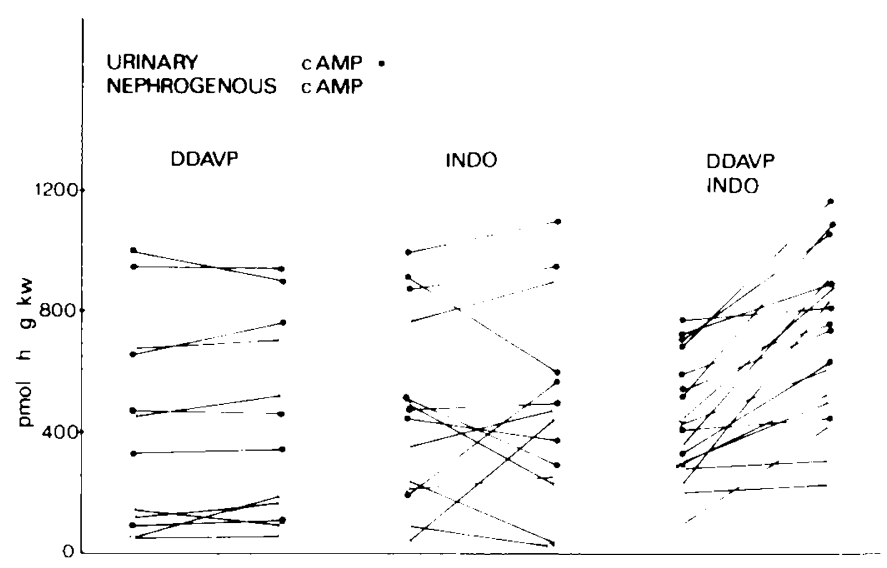

Fig. 1. Total urinary and nephrogenous cAMP before and after administration of DDAVP, indomethacin, and DDAVP plus indomethacin $k w$, kidney weight.

Table 1. Effect of DDAVP, indomethacin, and DDAVP plus indomethacin on urinary concentration, creatinine clearance, total urinary cAMP excretion, nephrogenous $c A M P$, and $P G E_{2}$ and $P G F_{2,}$

\begin{tabular}{|c|c|c|c|c|}
\hline & & DDAVP & Indomethacin & $\begin{array}{l}\text { DDAVP plus } \\
\text { indomethacin }\end{array}$ \\
\hline \multirow[t]{2}{*}{ Urinary flow rate $(\mathrm{ml} / \mathrm{hr})$} & Before & $2.0 \pm 0.5^{1}$ & $2.2 \pm 0.4$ & $2.4 \pm 0.4$ \\
\hline & After & $2.3 \pm 0.5$ & $2.1 \pm 0.7$ & $1.4 \pm 0.3^{2}$ \\
\hline \multirow[t]{2}{*}{ Urinary osmolality (mOsm/liter) } & Before & $473 \pm 35$ & $424 \pm 20$ & $444 \pm 29$ \\
\hline & After & $487 \pm 31$ & $426 \pm 45$ & $552 \pm 33^{\prime \prime}$ \\
\hline \multirow[t]{2}{*}{ Creatinine clearance $(\mathrm{ml} / \mathrm{min} / \mathrm{g}$ kidney weight $)$} & Before & $0.18 \pm 0.05$ & $0.19 \pm 0.04$ & $0.17 \pm 0.03$ \\
\hline & After & $0.17 \pm 0.06$ & $0.17 \pm 0.06$ & $0.16 \pm 0.05$ \\
\hline \multirow{2}{*}{ Total urinary cAMP (pmoles/hr/g kidney weight) } & Before & $588.5 \pm 143.7$ & $635.5 \pm 112.8$ & $590.0 \pm 47.9$ \\
\hline & After & $587.0 \pm 136.8$ & $637.5 \pm 111.3$ & $853.8 \pm 77.8^{3}$ \\
\hline \multirow{2}{*}{ Nephrogenous cAMP (pmoles/hr/g kidney weight) } & Before & $261.5 \pm 105.0$ & $319.5 \pm 95.4$ & 302.3 \\
\hline & After & $295.5 \pm 112.5$ & $340.1 \pm 114.8$ & 590.3 \\
\hline \multirow{2}{*}{$\mathrm{PGE}_{2}$ (pg/hr/g kidney weight) } & Before & $236.8 \pm 46.7$ & $353.1 \pm 57.0$ & $248.6 \pm 33.2$ \\
\hline & After & $229.0 \pm 56.2$ & $76.0 \pm 16.0^{4}$ & $19.3 \pm 3.5^{4}$ \\
\hline \multirow{2}{*}{$\mathrm{PGF}_{2 \mathrm{2n}}(\mathrm{pg} / \mathrm{hr} / \mathrm{g}$ kidney weight $)$} & Before & $157.2 \pm 20.9$ & $288.1 \pm 35.1$ & $192.1 \pm 31.7$ \\
\hline & After & $164.5 \pm 30.6$ & $85.7 \pm 17.9^{4}$ & $42.6 \pm 7.1^{4}$ \\
\hline
\end{tabular}

\footnotetext{
${ }^{1}$ Mean \pm S.E.

${ }^{2} P<0.05$

${ }^{3} P<0.01$.

${ }^{4} P<0.001$.
} 
Table 2. Medullary cAMP content in the control, DDAVP, indomethacin, and DDAVP plus indomethacin groups

\begin{tabular}{lcccc} 
& Control & DDAVP & Indomethacin & $\begin{array}{r}\text { DDAVP plus } \\
\text { indomethacin }\end{array}$ \\
$\begin{array}{l}\text { No. of samples } \\
\text { cAMP content (pmoles/g medulla) }\end{array}$ & 8 & 18 & 14 & 18 \\
\hline
\end{tabular}

'Mean \pm S.E.

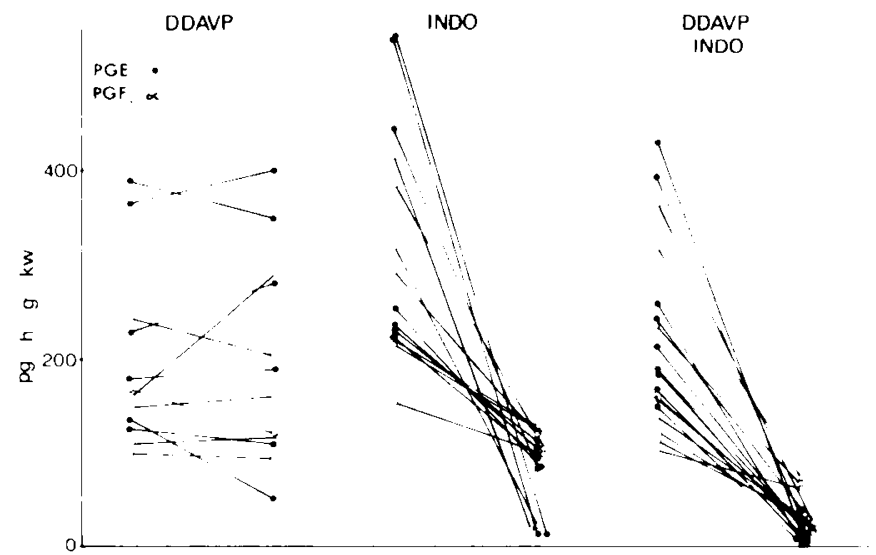

Fig. 2. $\mathrm{PGE}_{2}$ and $\mathrm{PGF}_{2,2}$ before and after the administration of DDAVP, indomethacin, and DDAVP plus indomethacin.

without any effect on nephrogenous cAMP excretion and on urinary concentration; (2) nephrogenous cAMP excretion and urinary concentration increased simultaneously after administration of DDAVP when renal PG excretion was reduced by indomethacin.

(Addendum 1) The finding that even supramaximal doses of DDAVP did not affect urinary concentration in newborn conscious piglets is consistent with previous observation on anaesthetized animals (14). As discussed there, the uneffectiveness of DDAVP on the renal concentration system results not so much from the general immaturity of the newborn renal concentrating system but predominantly from the reduced responsiveness of the medullary CAMP system which is known to mediate the antidiuretic effect of $\mathrm{ADH}(6)$. The view of the unresponsiveness of the medullary cAMP system as an important reason for the uneffectiveness of $\mathrm{ADH}$ in urinary concentration is also supported in this study. When urinary concentration is increased, total urinary and nephrogenous cAMP excretion increases as well. In addition, the renal medullary cAMP content is also increased. When the administration of DDAVP was without any effect on urinary concentration, total urinary and nephrogenous cAMP excretion and medullary cAMP content remained also unchanged.

(Addendum 2) It is unlikely that the increase in urinary concentration and nephrogenous cAMP excretion after administration of both DDAVP and indomethacin is due to a direct effect of indomethacin. When only indomethacin was administered, it did not induce any change in cAMP excretion and urinary concentration. However, indomethacin could have acted indirectly by its inhibitory effects on renal PG synthesis which is also demonstrated in this study by its decreasing effects on urinary PG excretion. $\mathrm{PGE}$ is known to interfere with the hydro-osmotic action of $\mathrm{ADH}$ $(1,3,8,10,17)$. Inasmuch as in the neonate piglet $\mathrm{PGE}_{2}$ synthesis is increased relative to $\mathrm{PGF}_{2,}$ as observed in other newborn mammals $(15,19,23)$ [the opposite was found in the adult state (21)]. One may assume that during this period the stimulatory effect of DDAVP on the medullary cAMP formation is prevented by the endogenous renal PGs of the E-series.

This assumption of an indirect action of indomethacin is not contradicted by the observation that the administration of only indomethacin remained without any significant response of the urinary cAMP excretion. As pointed out in an earlier report (12), in newborn animals the secretion of ADH is small when compared to adults. Under our experimental conditions, the endogenous ADH levels might have been too small to stimulate the medullary cAMP formation at a sufficient rate.

Thus, these data suggest that during the neonatal period the uneffectiveness of $\mathrm{ADH}$ on the urinary concentrating capacity results not only from the immaturity of the medullary cAMP system but also from the inhibitory effect of the endogenous $\mathrm{PGE}_{2}$ levels. However, because after the inhibition of renal PG synthesis and even after supramaximal doses of DDAVP the increase in urinary concentration was small as compared to the adult pig (18), our data demonstrate that further components of the countercurrent system must be immature.

\section{REFERENCES AND NOTES}

1. Anderson. R. J.. Berl. T.. McDonald, K. M.. and Schrier, R. W.: Evidence for an in vivo antagonism between vasopressin and prostaglandin in the mammalian kidney. J. Clin. Invest., 56: 420 (1975).

2. Barnett. H. L., Hare. K., and McNamara, H.: Measurement of glomerular filtration rate in premature infants. J. Clin. Invest.. 27: 691 (1948).

3. Berl. T., Raz. A.. Wald. H.. Horowitz. J., and Czaczkes. W.: Prostaglandin synthesis inhibition and the action of vasopressin: studies in man and rat. Am. J.Physiol., 2.32: F 529 (1977).

4. Bonsnes, R. W.. and Taussky. H. H.: On the calorimetric determination of creatinine by the Jaffe reaction. J. Biol. Chem., 158: 581 (1945).

5. Boss. J. M. N.. Dlouha. H., Kraus, M., and Krecek. J.: The structure of the kidney in relation to age and diet in white rats during the weaning period. $J$. Physiol. (Lond.). 168: 196 (1963).

6. Dousa. T. P., and Valtin, H.: (ellular actions of vasopressin in the mammalian kidney. Kidney Int., 10: 46 (1976).

7. Edelman. (. M.. Jr.. Barnett, H. L.. and Troupkou, V.: Renal concentrating mechanism in newborn infants. Effects of dietary protein and water content. role of urea, and responsiveness to antidiuretic hormone. J. (Clin. Invest.. 39: $1062(1960)$.

8. Fejes-Tóth, G.. Magyar, A... and Walter. J.: Renal response to vasopressin after inhibition of prostaglandin synthesis. Am. J. Physiol., 2.32: F416 (1977).

9. Gilman. A. (j.: A protein binding assay for adenosine 3, 5'-monophosphate. Proc. Natl. Acad. Sci. U. S. A.. 67: 305 (1970).

10. Grantham. J. J.. and Orloff. J.: Effect of prostaglandin $E_{1}$ on the permeability response of the isolated collecting tubule to vasopressin, adenosine $3^{\prime}, 5^{\prime}$-monophosphate and theophylline. J. Clin. Invest.. 47: 1154 (1968).

11. Hamet. P., Kuchel, O., Fraysse. J.. and Genest. J.: Plasma adenosine-3'.5'-cyclic monophosphate in human hypertension. Can. Med. Assoc. J.. 11: 323 (1974).

12. Heller, H.. and Lederis, K.: Maturation of the hypothalamoneurohypophysial system. J. Physiol. (Lond.), 147: 299, (1959).

13. Jacobs. K. H.. Böhme. E., and Schultz. G.: Determination of cyclic (iMP in biological material. In: J. E. Dumont. B. L. Brown. N. J. Marshall: Eukariotic cell function and growth. Regulation by intracellular cyclic nucleotides. p. $295-$ 311 (Plenum Press. New York, 1976).

14. Joppich. R.. Kiemann. U., Mayer. G.. and Häberle. D.: Effect of antidiuretic hormone upon urinary concentrating ability and medullary cAMP formation in neonatal piglets. Pediatr. Res., 13: 884 (1979).

15. Joppich. R.. Scherer, B.. and Weber, P. C.: Renal prostaglandins: relationship to the development of blood pressure and concentrating capacity in pre-and full term healthy infants. Eur. J. Pediatr., 132: 253 (1979).

16. Kirschenbaum, M. A.. White, N.. Stein. J. H., and Ferris. T. F.: Redistribution of renal cortical blood flow during inhibition of prostaglandin synthesis. Am. J. Physiol.. 227: 801 (1974).

17. Lum. G. M.. Aisenbrey. G. A.. Dunn, M. J., Berl. T., Schrier, R. W.. and McDonald. K. M.: In vivo effect of indomethacin to potentiate the renal medullary cyclic AMP response to vasopressin. J. Clin. Invest., 59: 8 (1977).

18. O'Dell, R., and Schmidt-Nielsen. B.: Concentrating ability and kidney structure. Fed. Proc.. 19:366 (1960)

19. Pace-Asciak. C. R.: Prostaglandin biosynthesis and catabolism in the developing fetal sheep kidney. Prostaglandins, 13: 661 (1977).

20. Rajerison. R. M.. Butlen. D., and Jard. S.: Ontogenic development of antidiuretic hormone receptors in rat kidney: comparison of hormonal binding and adenylate cyclase activation. Mol. Cell. Endocrinol., 4: 271 (1976). 
21. Scherer, B., Siess, W., and Weber, P. C.: Radioimmunological and biological measurements of prostaglandins in rabbit urine: decrease of $P G E_{2}$ excretion a high $\mathrm{NaCl}$ intake. Prostaglandins, 13: 1127 (1977).

22. Schlondorff. D.. Weber, H.. Trizna, W., and Fine, L. G.: Vasopressin responsiveness of renal adenylate cyclase in newborn rats and rabbits. Am. J. Physiol. 234: F16 (1978).

23. Walker, D. W., and Mitchell, M. D.: Prostaglandins in urine of foetal lambs. Nature (Lond.), 27l: 161 (1978).

24. Zins, G. R.: Renal prostaglandins. Am. J. Med.. 58: 14 (1975)

Copyright $(1981$ International Pediatric Research Foundation, Inc. $0031-3998 / 81 / 1503-0278 \$ 02.00 / 0$
25. The invaluable technical assistance of I. Berger and B. Bohlig is gratefully acknowledged.

26. Requests for reprints should be addressed to: Dr. Rudiger Joppich. UniversitatsKinderklinik, Lindwurmstrasse 4, D-8000 Munich 2, Federal Republic of Germany.

27. This research was supported by Deutsche Forschungsgemeinschaft. Bonn-Bad Godesberg. Federal Republic of Germany.

28. Received for publication April 30, 1980.

29. Accepted for publication July 15, 1980. 